\title{
VIDA COTIDIANA EN LA COMUNIDAD WIXARIKA EL COLORÍN: MEMORIA Y HERENCIA DE UN MARA'AKAME: JOSÉ RÍOS (MATSIWA)
}

Everyday life in the Wixarika community El Colorín: remembrance and inheritance of a mara’akame: José Ríos (Matsiwa)

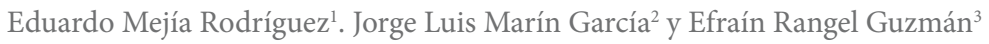

Fecha de recepción: 4 de noviembre de 2019

Fecha de aceptacion: 11 de febrero de 2020

1- Nacionalidad: Mexicana. Grado: Maestría en Administración. Adscripción: Universidad Autónoma de Nayarit Correo electronico: ed2205@hotmail.com. (DD ORCID: https://orcid.org/0000-0002-3840-783X

2- Nacionalidad: Mexicana. Grado: Doctorado en Ciencias Sociales. Adscripción: Universidad Autónoma de Nayarit. Correo electronico: jorgemarin4761@hotmail.com. (iD ORCID: https://orcid.org/0000-0001-6050-8840

3- Nacionalidad: Mexicana. Grado: Doctorado en Antropología. Adscripción: Universidad Autónoma de Ciudad Juárez. Correo electronico: efrain.rangel@uacj.mx; rangelefra@hotmail.com. (DD ORCID: https://orcid.org/0000-0003-4987-553X 


\section{Resumen}

En la comunidad wixarika El Colorín, en el municipio de Del Nayar, Nayarit, México, se realizan principalmente dos actividades económico-productivas: la pesca y la elaboración de arte huichol. También hay un incipiente turismo y una arraigada pero mermada ganadería, al igual que una casi extinta agricultura. Pero no siempre ha sido así, dado que en algún momento predominó la agricultura y en otro momento la artesanía. Para comprender las transformaciones y reacomodos que sucedieron para llegar a lo que ahora acontece en El Colorín, se propone analizar la vida cotidiana en la región de Aguamilpa, desde el individuo socializado en un espacio y tiempo determinado, a partir de la figura de José Ríos (Matsiwa), desde una escala microsocial. A tal fin se exponen los modos de vida, especialmente de dos periodos, como fotografías que muestran la forma en que se ha vivido en la región.

Palabras clave: José Ríos (Matsiwa), El Colorín Nayarit, wixaritari.

\section{Abstract}

In the Wixarika community El Colorin, in Del Nayar municipality, Nayarit, México, two economic-productive activities are mainly carried out: fishing and the elaboration of Huichol art. There is also incipient tourism and ingrained but depleted livestock, as well as an almost extinct agriculture. But this has not always been the case, due to at some point agriculture predominated and at another time craftsmanship. In order to understand the transformations and re-accommodates that happened to reach what is now happening in El Colorin, it is proposed to analyze the everyday life in the Aguamilpa region, from the socialized individual in a particular space and time, based on the figure of José Ríos (Matsiwa), from a microsocial scale. To this purpose, the ways of life, especially from two periods, are presented as photographs showing the way in which it has been living in the region.

Keywords: José Ríos (Matsiwa), El Colorín Nayarit, wixaritari 


\section{Introducción}

$\mathrm{L}$

os wixaritari o huicholes son uno de los grupos indígenas más estudiados en México, destacando el arte y la religión como los aspectos más abordados. En dichos trabajos, según (Marín, 2011: 113), encontramos "numerosos relatos sobre la vida y obra de los miembros de esa etnia llenos de pasajes fantásticos, narraciones increíbles y de crudas realidades forjando una imagen mística y llena de misterio..."

Los trabajos publicados sobre los wixaritari, aunque no necesariamente etiqueten a sus protagonistas como jaliscienses, en términos generales se adscriben a prácticas culturales en el estado de Jalisco, y son realmente pocos los que se refieren a los wixaritari de Nayarit (Jaúregui, 2003; Tellez, 2005; Santos, 2017; Tellez y Le Mûr, 2017, entre otros), quizás por considerar que: a) no hay diferencias culturales significativas entre quienes habitan un estado u otro, o peor aún que b) por los cambios culturales, resultado de la "contaminación" de la cultura occidental, no vale la pena investigar entre los wixaritari que viven en tal Estado.

Como intento de respuesta a lo anterior, se propone que:

a) sí hay diferencias culturales significativas entre quienes habitan un estado $u$ otro, $y$ más en regiones como la de Aguamilpa, que abarca poblados cercanos a la presa del mismo nombre, y los de El Corredor Aguamilpa-Tepic que va de allí a la ciudad de Tepic.

b) conocer la forma en que se ha desarrollado la cultura wixarika en sitios distintos al conocido como territorio tradicional, permite entender la manera en que se adaptan formas de vida costumbres y tradiciones en contextos distantes al lugar de origen conservando un núcleo duro de el costumbre 4 pese a las modificaciones que las nuevas condiciones demandan, con la intención de mantener lazos importantes con el lugar de origen.

Es posible que la diferencia más importante radique en los modos de vida entre una región como la de Aguamilpa y aquellas en Jalisco, profusamente documentadas. Por otra parte, aunque localidades como El Colorín a primera vista parecieran generar modos de vida similares a los que se pueden observar en muchos poblados rurales mestizos, todo cambia cuando se observan a profundidad aspectos como rituales, lengua y arte; cuya práctica o concepción permiten establecer claras distinciones en las dinámicas socioculturales de ambos tipos de poblaciones.

Para intentar comprender las dinámicas socioculturales desarrolladas en El Colorín, nos apoyamos en el concepto de vida cotidiana, una herramienta teórica-metodológica proveniente de la sociología de la vida cotidiana que aborda al individuo dentro de un contexto donde la realidad es interpretada por quienes la viven, a partir de que comparten sistemas que dan coherencia a su mundo. Desde la escala microsocial, este concepto es entendido por Lefebvre (1981), como la vida real, la que se encuentra en el

4- "El costumbre son las prácticas culturales que se dice fueron dejadas por los ancestros y que se pueden observar en el ciclo ritual de ceremonias wixaritari, pero también en distintos ámbitos de la vida cotidiana wixarika pues pertenece a lo considerado como de tiempos inmemorables" (Marín, 2011: 275). 
encadenamiento de los actos diarios, fuera del análisis del mundo de las ideas que finalmente conforma un todo. Por ello, "la vida cotidiana aparece como el lugar (locus) de la producción y de la reproducción de los ritmos socioculturales, y de su articulación con los ritmos siderales" (D'Epinay, 2008: 14). Finalmente, lo que se busca es conocer "un conjunto de relaciones sociales que se dispersan en distintos espacios de vida y se fragmentan en diferentes tiempos" (Lindón, 1997: 178).

El interaccionismo simbólico de Berger y Luckman, del que abrevan D’Epinay y Lindón, sitúa a un individuo socializado que comparte significados, donde el lenguaje es sumamente importante y las estructuras espacio temporales nos ponen en contacto con los otros. En sus palabras, la "estructura temporal proporciona la historicidad que determina mi situación en el mundo de la vida cotidiana" (Berger y Luckman, 1986: 7). Tal idea de historicidad permite visualizar un hilo que conecta los modos de vida en El Colorín con individuos como don José Ríos (Matsiwa). ${ }^{5}$ En ese orden de ideas, los seres humanos, son "sujetos-cuerpos que habitan diversos lugares, de distintas formas [...]. Para el sujeto, el espacio es relevante porque forma parte de las condiciones insoslayables de la vida" (Lindón, 2011: 17-18).

El presente documento quiere centrar la atención en el proceso de transmisión de prácticas económicas, culturales e identitarias del periodo en que don José vivió y sobre la influencia de él en periodos posteriores en el entorno familiar y comunitario, a partir de lo productivo.

Si dividiéramos la historia de la familia Ríos Medrano, a partir de la vida de don José, podemos pensar en dos etapas, marcada cada una por una actividad productiva preponderante: a) La agricultura y b) El chamanismo y el arte huichol. Una tercera, producto de las anteriores, pero sin la presencia de don José, se encuentra firmemente ligada a la pesca como actividad productiva, aunque ello no implica la desaparición total de las actividades productivas que marcan las etapas anteriores.

El trabajo se presenta en tres apartados; al primero de ellos se denomina: La familia Ríos Medrano y la agricultura antes de 1965, donde se intentará narrar de manera muy general la vida de don José y el papel de la familia; así como las migraciones que realizaron y cuál era el modo de vida de la familia Ríos, hasta antes de 1965. En el segundo apartado, La familia Ríos Medrano, el chamanismo y el arte huichol, se pretende narrar de forma somera la manera en que se entretejen redes en torno a don José Ríos, a partir de la introducción a la comunidad de Peter Furst por Ramón Medina, primer artista wixarika reconocido como tal en Estados Unidos, y de personajes como Prem Das y Brant Secunda, responsables de introducir al mara’akame ${ }^{6}$ José Ríos (Matsiwa) y sus artes chamánicas, ante cierto público norteamericano; el tercer apartado, el más pequeño, es denominado El legado de don José Ríos (Matsiwa), en él se intentan

5- Como una forma de respeto a las prácticas culturales wixaritari, en el desarrollo del texto podríamos hablar de Matsiwa en lugar de don José Ríos, dado que Matsiwa es el nombre wixarika del personaje criticado por algunos (Fikes; Fikes y Weigand) y reverenciado por otros (Das, 1978; Grof, 2018). Empero, en el contexto en que se está realizando la investigación, don José es quien aparece generalmente en el diálogo, mientras que Matsiwa sólo hace acto de presencia cuando preguntan por él con ese nombre quienes escriben este artículo.

6- El mara’akame es un médico tradicional del pueblo wixarika, que atiende la salud en lo físico y espiritual, desde el plano de lo comunitario, dado que todo mal y todo bien provienen de la comunidad conformada por los wixaritari actuales y los ancestros, incluyendo los ancestros divinizados. La enfermedad y los problemas sociales provienen de un desequilibrio en la comunidad, uno recurrente es el de la falta de reciprocidad con los ancestros divinizados: en los primeros tiempos ellos se sacrificron para que los habitantes del mundo pudieran vivir de la mejor manera posible y por tanto, los wixaritari deben sacrificarse haciendo Fiestas y ceremonias donde regresan un poco de lo recibido de los ancestros. La falta de reciprocidad ocurre cuando alguien que está vivo no hace las Fiestas o ceremonias debidas, no acudió a ellas o no las hizo como debía; pero también puede haber mal físico o social cuando un pariente murió sin cumplir. El mara'akame es un especialista religioso quien por medio del sueño descubre las razones por las que existe la enfermedad y tiene el don de platicar con los ancestros divinizados y convocarlos a las ceremonias por medio del canto. 
plasmar algunos de los aspectos que constituyen el legado de José Ríos y que todavía dan forma a modos de vida actuales entre habitantes de El Colorín.

\section{La familia Ríos Medrano y la agricultura antes de 1965}

A finales del siglo XIX en la dinámica de las guerras, guerrillas y revueltas, un militar de rango robó varias mujeres en Zacatecas, entre ellas a Angelita Ríos Cabada, joven mestiza que sería dada como pareja a Candelario de la Rosa de la Cruz, hombre huichol originario de Santa Catarina (Tuapurie) en el actual municipio de Mezquitic, al norte del estado de Jalisco. Angelita y Candelario se convertirían en los padres de José. Así lo narra Epifanio, hijo de don José:

[...] El jefe por ahi agarró viejas donde quiera, se trajo como unas treinta. Se las repartió. A mi papa ${ }^{7}$ [abuelo] le dejaron a mi abuelita, y mi abuelito no, pos no dormía con ella, le tenía miedo, pues era deatiro huicholito pues, cerrado, no hablaba español, yo creo nada. Y ahi anduvo, ahi anduvo, lo que hizo mi abuelita, se enseñó a hablar en huichol. No se quiso ir ya, [dijo ella] no pos ahí, pa' onde me voy ya. Y luego lejos, pos zacatecas ya ves que estaba lejos [...]. Ya anduvo con ellos [en la revuelta], pos [mi abuela] le echaba tortillas y le daba de comer (Epifanio, 2019). ${ }^{8}$

Probablemente después de la revuelta, Candelario regresó junto con su mujer a Santa Catarina, en la sierra de Jalisco. La familia integrada por Angelita y Candelario, tuvo como descendencia a José, Andrés, Esteban, Carlos, Teresa y Jesusita. De ellos, José era el mayor y llegaría a la región Aguamilpa como a los ocho o diez años. De acuerdo con doña Emilia (2019), él, sus hermanos y hermanas nacieron para el lado de Santa Catarina en la sierra de Jalisco.

La razón para abandonar las tierras jaliscienses, podría ser alguna o algunas de las diferentes luchas armadas que atravesaron el territorio, el hambre o la combinación de ambas situaciones: "se vinieron pa' la costa, venían al trabajo pues, ya no se quisieron regresar porque pos estaba bueno, había mucha comida aquí, había plátanos y bueno muchas cosas había y allá no había nada” (Epifanio, 2019).

Algunos años después de la llegada a la región de Aguamilpa, doña Emilia asegura que se llevaron al joven José y a sus padres a "La Villada" (movimiento armado de los villistas entre 1913 y 1915), seguramente fueron parte de enfrentamientos. Aparentemente duraron poco en la revuelta, pues los padres de don José:

7- A lo largo del texto hay expresiones como mama, papa y ahi, que en una escitura correcta llevarían tilde porque se refieren a mamá, papá o ahí; sin embargo los autores preferimos una transcripción verbatim de lo dicho por las personas entrevistadas porque justamente el respeto a sus expresiones forma parte de la comprensión del contexto cultural donde ha desarrollado la vida de la gente que compartió sus historias con nosotros. Del mismo modo, transcribir las expresiones tal como fueron escuchadas permite dar cuenta de la riqueza lingüística existente en esa región del país, dado que no hay formas incorrectas de hablar y si musicalidades múltiples.

8- Epifanio Ríos Medrano, entrevista relizada en Tepic, Nayarit, el 08 de abril de 2019 en El Colorín, mpio. de Del Nayar. 
se juyeron, no les gustó porque andaban sin comer. Onde había, dizque nomás vaca mataban, iban a asar carne, se iba cociendo se las quitaban dizque. Y de hambre mejor se vinieron. En la noche dizque nomás se acostaron, jándale! agarraron pa'l monte y se vinieron a la fregada y vinieron a dar en Roseta (Emilia, 2019). ${ }^{9}$

Candelario y Angelita se escaparon solos. Por ello, narra Emilia que contaba: ... a mí una vieja aquí me dio un balazo, sabia decir mi papa, una cabrona galleta ${ }^{10}$ me dió en la pata. Por ese motivo se salió y se vino. Le reclamaba a sus papas por haberlo dejado allá: mama cuando se vinieron no me dijeron, yo me habría venido también escondido (Emilia, 2019).

Tras el balazo, fue a dar hasta Roseta donde encontraría a su mamá, para ese tiempo José ya era un adolescente pues ya portaba un arma y participaba en la revuelta, pero seguramente era joven, pues señala Emilia (2019), "mi papa allí se acabó de criar".

En Roseta, "Ya de criado mi papa ya trabajó en la vía". Las vías del tren que conectaban Tepic con los estados del norte del país fueron inauguradas en 1912, en ese mismo año, por los efectos de la Revolución serían destruidas de forma parcial, e inmediatamente empezarían a reconstruirlas y ampliarlas. Para 1927 se inauguraría la vía de ferrocarriles Guadalajara-Tepic (Meyer, 1997).

Mientras trabajaba construyendo las vías del tren, José conoció a su primera mujer quien fallecería a los pocos años de dar a luz a Andrea. Tras enviudar, se casó con Josefa, hermana de su difunta esposa y originaria de San Andrés Cohamiata (Tateikie), en el actual municipio de Mezquitic, al norte del estado de Jalisco, quien habría llegado a "la costa" al cuidado de su abuela. Al tiempo, los Ríos-Medrano se irían a San Miguel, en el municipio Del Nayar, donde nacieron Emilia y Juana. Después llegaron a vivir a Cerritos en el municipio de Tepic, donde nacieron Catarino, Maximiliano, Epifanio, Mariana y Elías. Asegura Emilia (2018) que Cerritos era una comunidad grande, hasta tenía escuela a donde asistieron ella y Juana. Juan, Virginia y José, hijos de Emilia, nacieron en La Mesita.

Los principales lugares habitados por la familia Ríos dentro de la región de El Colorín, a partir de la época de llegada y hasta la década de 1980 fueron: San Miguel, Cerritos, Guamiloya-Gualamito, El Papayo, La Cuatantera y La Mesita; vale la pena aclarar que algunos lugares mencionados son sólo puntos de referencia convertidos en localidad al ser habitados por la familia Ríos. De acuerdo con las narraciones de los actuales Ríos, el motivo principal para migrar fue la búsqueda de tierras para sembrar, especialmente maíz.

9- Emilia Ríos Medrano, entrevista reaizada en el 01 de marzo de 2019 en El Colorín, mpio. de Del Nayar

10- "Galleta" era una forma de llamar a las soldaderas, mujeres que como esposas y/o compañeras sexuales acompañaban a los hombres en los peligros de la lucha armada durante la Revolución, a veces voluntariamente, a veces por la "leva". Pero no solo eran acompañantes, muchas tomaron las armas y aunaron el guerrear a atender a los soldados (Rocha, 2015). 


\section{Ascendencia y descendencia de don Jose Ríos (Matsiwa)}

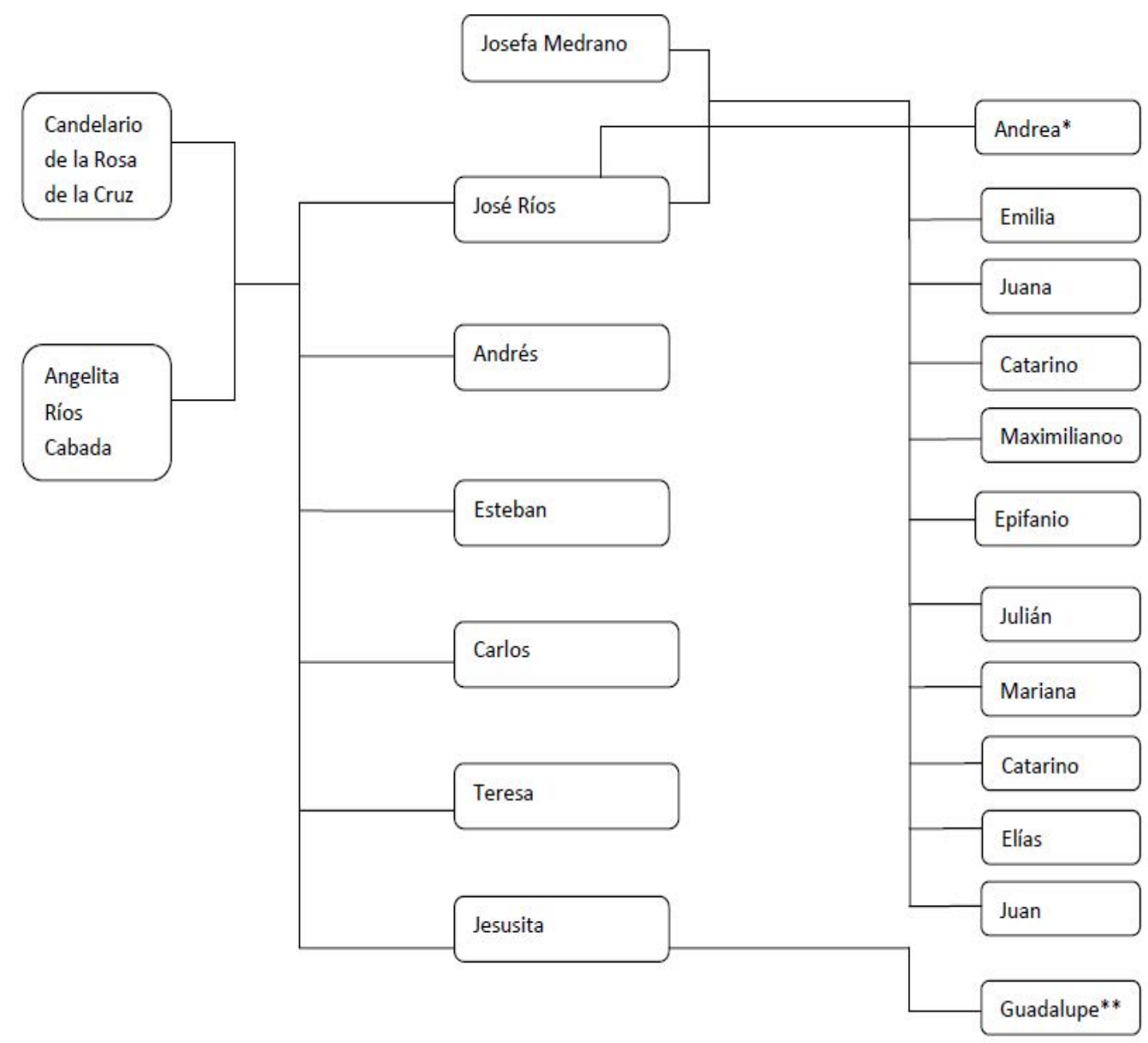

${ }^{\star}$ Hija mayor. Hija de don José y su primera esposa. Fue mara'akate en la comunidad Salvador Allende, en el municipio de Tepic .

${ }^{*}$ Guadalupe Ríos, esposa del reconocido artista huichol Ramón Medina, sobrina de don José Ríos.

\subsection{El maíz}

El maíz marca la primera etapa de la vida en comunidad de la familia Ríos-Medrano. En aquel tiempo y como en otros lados, la idea era que, para hacer producir el campo, se requerían familias grandes; eso tenía don José para obtener cosechas abundantes. Narran que don José comenzaba sus labores a las cuatro de la mañana y ponía tareas a sus hijos e hijas, con la encomienda de que, quien terminara se podía ir; aunque la 
otra cara de la moneda era que, de acuerdo con el espíritu de la época, no hacer bien el trabajo, implicaba un castigo, la amenaza siempre era una cueriza. ${ }^{11}$

Emilia y Mariana hijas de don José, recuerdan esos años en que se dedicaban a cultivar el maíz:

Todas trabajábamos como hombres. Todas las mujeres sembrábamos, limpiábamos. Pizcábamos con las petacas [chiquihuites], cada quien saz, saz, como los hombres por surco. Desgranábamos el maíz todos, las mujeres y los hombres (Emilia, 2018). [Ya casadas] le ayudábamos a mi papa a levantar toda su cosecha y ya nosotros ya sembrábamos lo de nosotros, porque pos los maridos de nosotros sembraban muy poquito y mi papa no, él tumbaba muchísimo. Nos daba una medida de maíz que son cinco litros pa' todo el día, lo teníamos que acabar, para sembrarlo. Y nos ponía "de a cinco granitos, de a cinco granitos, y si hallo seis o siete granitos que nazcan [...] los voy a cueriar". No, pos nos amagaba feo. "El que acabe primero se va". No'mbre, nosotros por no dejarnos ni descansábamos, saz, saz, saz, con pichuaca. ${ }^{12}$ No nos dejábamos, era jodida, bueno como un hombre pues. A rociar... iban a rociar y nos llevaban a acarriar agua a nosotros, en el lomo, bules grandes, "canchidos" ${ }^{13}$ Ahí andábamos, todo el día (Mariana, 2018). ${ }^{14}$

Mi papa nos decía, de aquí allá y allá, vas a limpiar tú; tú también allá. Nos daba partes... el que acabe primero se va.... Pero dijo, "voy a estar revisando, si hay yerbitas pegado, me los voy a..." [hace seña de golpear con la palma de las manos]. ¡No pos quien iba a dejar yerbas pegadas! ¡No'mbre, a puro machete!

A las cuatro ya estaba almorzando para irse a trabajar él. Mi mamá se levantaba como a las tres y media porque éramos once de familia. Molía en el metate ella y torteaba a mano. Sabía tener un guaje ${ }^{15}$ así, por aquí así de altote [capacidad de unos seis kilos], llenaba bien el tecomate, ${ }^{16}$ arriba todavía un alterón así [de tortillas], no pos [para] un puño de muchachos. Mi mama trabajaba mucho, cuando después que ya hubo molino nos ponían a moler en el molino, y si no queríamos, no, unos cuerazos que nos daba (Emilia, 2018)

En tiempo de cosecha, narran Emilia y Mariana que a ellas les tocaba cargar los burros, en grupos de diez, a cada lado de cada burro le cargaban diez medidas. ${ }^{17}$ Una vez todos cargados, una se iba delante de

11- Cueriza: azotaína dada con cinturón, soga o incluso otros objetos como cables y el denominado regionalmente "chile de toro", utilizado para fustigar animales y a veces a humanos. También puede ser una serie de golpes dados con palos, zapatos y muchas otras cosas al alcance de quien golpea.

12- La "pichuaca" es un tipo de coa, una herramienta "a manera de espátula que se coloca en un extremo de un otate" (Godoy, 2004: 28) o de un palo para sembrar.

13- "Canchido": cargado en la espalda

14- Mariana Ríos Medrano, entrevista realizada en el 09 de marzo de 2018 en El Colorín, mpio. de Del Nayar.

15- Guaje: se llama así a la planta o fruto de la lagenaria siceraria. En el contexto de la entrevista, es una vasija hecha con el fruto de la lagenaria siceraria.

16- Tecomate: vasija honda de barro o de guaje. En el contexto de la entrevista, es sinónimo de la vasija llamada guaje.

17- Medida: recipiente para medir volúmenes equivalente al celemín, que consiste en 4.6 litros. 
los diez burros y otra atrás arreando, hasta donde vivían. Los hombres, por su parte, cargaban a los machos. Los elotes, cuando ya estaban secos, eran desgranados por todos, hombres y mujeres. "Sabemos cargar leña, sabemos cargar maíz [...] y subirnos en los burros, yo no les tengo miedo...” (Mariana, 2019).

\subsubsection{Viviendo del maíz}

En ese tiempo, la siembra del maíz era la actividad preponderante, de allí comían y el sobrante lo vendían. También poseían vacas, puercos y gallinas, perros y remudas. Además del maíz, se sembraba y cosechaba frijol y calabaza para consumo de la familia. Las actividades asociadas al coamil, posiblemente constituían la parte más importante de la educación para ser un wixarika competente.

Don José y doña Josefa educaban a sus hijos e hijas, ella se aseguraba que las mujeres aprendieran lo que una mujer de la época y contexto debía saber: cocer el nixtamal, moler y echar tortillas, zurcir, tejer y coser, y como ya se mencionó, trabajar en el campo. Algo similar sucedía con los hombres, además de aprender a trabajar el campo, a cierta edad les tocaba echarse sus tortillas. La enseñanza no terminaba ahí, cada cierto tiempo, a la luz de la lumbre don José les daba consejos a sus hijos, les advertía de la importancia del respeto a lo ajeno y la convivencia en familia.

Esos tiempos en que se sentaban alrededor de la fogata es parte de lo que recuerdan como tiempos libres. Los juegos que rememoran son cuando montaban un viejo cuero de vaca y se resbalaban por las bajadas. Ir al río también lo disfrutaban, mientras los más grandes pescaban, cazaban o juntaban frutas y legumbres, los más chicos se bañaban y colgaban de guías para brincar al agua.

Como ya se mencionó, para aquella época la familia Ríos Medrano prácticamente constituía la comunidad. A medida que se casaron las hijas e hijos, la familia crecía, pero se mantenían unidos, el jefe era don José, él imponía los castigos a quienes cometían una falta. Por ejemplo, cuando una de sus hijas se escapó con un hombre casado, al tiempo que regresaron les pegó a ambos como reprimenda.

\subsection{E1 ritual}

No se puede dejar de lado la parte ritual, uno de los principales elementos que distingue las prácticas socializadas de esta comunidad en relación con las comunidades rurales mestizas de la región. Dado que hablar del ritual con relación al maíz es referirnos al pasado, pero también al presente e incluso al futuro incierto, nos permitiremos escribir sobre esta parte del documento en presente.

El maíz no solo era y es un alimento para los humanos actuales, también es ancestro directo de los wixaritari, alimento de los dioses y don otorgado a sus descendientes, los presentes wixaritari. Con el maíz se prepara el tejuino, el elemento indispensable para que los dioses se presenten en las fiestas. Por otra parte, el maíz representa al humano y a las familias, de allí que una forma de parentesco muy importante entre la gente wixarika sea la familia del maíz, la cual está formada por quienes siembran el coamil, sin importar el parentesco de la sangre. Realizar el costumbre, es lo que los mantiene sanos y salvos: 
mientras tamos vivos pos rezamos, hablamos a Dios, le hablamos a la lumbre, le hablamos a la tierra, le hablamos al agua. Que por eso hacemos sus ofrendas: pues para que nos de agua, nos dé el sol, ver bien, andar aquí en este mundo, que no nos pase nada. Todo le pidemos, por eso lo que hacemos para darle de comer todos a la tierra, le damos de comer porque la tierra es el que nos da el maíz (Mariana, 2018).

Marín (2011: 326) enuncia que las Fiestas ${ }^{18}$ son una de las formas en que los wixaritari fuera del llamado territorio tradicional ${ }^{19}$ continúan en relación con la cultura ancestral:

Tatei Neixa o Fiesta del tambor representa una de las principales puertas a la adquisición de la cultura de los ancestros, la cultura wixarika. [...] Tatei Neixa es la presentación de la geografía sagrada y de los ancestros sagrados a los niños. Al mismo tiempo que es la presentación de los niños ante los ancestros. [Así, dicha fiesta] se convierte en el mecanismo más usual, en cuanto a elementos festivos, para intentar tender un lazo hacia la cultura wixarika.

Jaime (2018) lo explica así:

esa Fiesta viene siendo como el maíz, es una milpa que es la familia... la raíz, todo eso, ahí estamos pegados, debemos estar juntos para que vaya el proceso, para que la milpa se de... Mi tío me dijo: si tú, por decir, mantienes limpia una milpa ... se ha de ir bonito, y pos todas las raíces de esa que está encima crece y se va metiendo a las piedras. Y por eso le dicen la Fiesta del Elote, porque todos los recién nacidos haz de cuenta que se van a apegar ahí (Jaime, 2018).

En relación con la cosecha, en Tatei Neixa, conocida entre los mestizos como Fiesta del Tambor, se sangran "las ofrendas y los elotes, todo lo que se va a cortar, todo se sangra y ya, que ya les da uno de comer porque ya los vamos a cocer" (Mariana, 2018). En tal celebración, también conocida como Fiesta de Nuestras Madres, lo más hermoso para propios y extraños eran y todavía son, los niños en sus trajes de huichol, quienes sonajean bajo el sol por varias horas.

Xarikixa (Fiesta del Esquite) y Tatei Neixa, dice doña Emilia que son las dos fiestas principales del maíz. Los mitos, relatos, bailes y demás elementos que componen las fiestas, están cargadas de símbolos y significados integrados en un sistema complejo accesible principalmente a los miembros del grupo.

18- En este artículo escribimos Fiesta o Fiestas con mayúscula cuando nos referimos a las Fiestas Neixa (Danza) de los wixaritari, para que no se confunda este tipo de celebración comunal perteneciente al ciclo agrícola-religioso anual wixarika con otros como pudiera ser un cumpleaños, por ejemplo.

19- Aquí se habla de "el llamado territorio tradicional" como una forma de diferenciar territorios como el habitado históricmente por los wixaritari de El Colorín a partir de finales del siglo XIX, con territorios que se reconoce ocupan de forma histórica los wixaritari al menos desde el contacto con los españoles y sus aliados, en el siglo XVI. De igual manera es una forma de relativizar la palabra tradicional, dado que cada nuevo espacio ocupado por los wixaritari (kie, rancho) puede ser enraizado en la tradición mediante "pedir prestado" ceremonialmente el fuego a un xiriki (templo familiar) antiguo, que a su vez está conectado a un tuki (templo de tipo comunal) junto con otros xirikite (pl. de xiriki), conectado a su vez a la hoguera primordial junto con los demás tukite (pl. de tuki), formando entre todos una gran estructura, el kiekari, mundo (ver Liffman, 2005). 
Una "realidad interpretada por los hombres y que para ellos tiene un significado subjetivo de un mundo coherente [...] estructura temporal orientadora" (Berger y Luckman, 1986, págs. 7-15)” al marcar los tiempos de cosecha y siembra.

\section{La familia Ríos Medrano, el chamanismo y el arte huichol}

Al inicio de la década de 1960 la familia Ríos ya vendía arte huichol a Ramón Medina, y de acuerdo con las narraciones, el dinero que ganaban con tal actividad, superaba con creces lo obtenido con el maíz. Pero todavía no se convertía en principal actividad productiva económica porque su producción debía ser fuera de La Mesita, especialmente en Guadalajara. Se puede decir que Ramón Medina acercó a la familia Ríos un elemento que transformó su vida cotidiana: el arte huichol. Les enseñó a elaborar arte huichol e hizo posible comerciar toda su producción. Ello provocó todo un cambio en las estructuras socioproductivas.

Hacia 1965 o 1966, Ramón Medina, a quien asesinarían en 1971, llevó a Peter Furst y Bárbara Myerhoff, los primeros antropólogos norteamericanos que iban a la región, a La Mesita, donde vivía la familia Ríos. La expresión de la cultura en el arte del ritual y la producción de piezas pronto interesó a los visitantes. Peter Furst pronto se convirtió en uno de los principales difusores del arte huichol, compraba a Ramón Medina principalmente cuadros y los vendía en Estados Unidos de América (Marín, 2011: 155).

De hecho, no se puede dar cuenta del auge el arte huichol en la región El Colorín sin la presencia de los no huicholes, porque además de sugerir ciertos cambios a piezas de arte huichol, también dieron amplia difusión a algunas de las prácticas culturales de los habitantes de la comunidad y reforzaron en el imaginario teiwari ${ }^{20}$ la idea de que el arte huichol y el chamanismo constituían un binomio indivisible.

Al tiempo, junto con Furst llegaban "americanos" interesados en la cultura y ávidos de conseguir piezas para museos o para sus colecciones personales, de acuerdo con los relatos:

Los americanos querían cosas antiguas, un metate [de] mi mamá por ahí así de ancho (40 cm aproximadamente), de esos de piedra sin patas, un "guilanchi" ochocientos dólares le dieron por un metate [Los artículos comprados eran para un museo]. Allí vendieron todo, hasta las muestras, me acuerdo que mi mamá tenía unas bolsas ya casi deshiladas [que también vendió] (Antonio, 2019). ${ }^{21}$

La ganancia económica y quizás la satisfacción del reconocimiento teiwari impulsaron a la elaboración del arte huichol y en el caso de don José al chamanismo fuera del territorio tradicional, como las actividades económicas productivas principales. La siembra del maíz, siguió siendo importante al ser la

20 - Teiwari (pl. teiwarixi): podría traducirse como no wixarika o de origen no wixarika; sin embargo, quienes forman parte de los pueblos originarios del Gran Nayar no son teiwarixi. El término aplicaría a cualquier persona, objeto o práctica que no se considere como originaria del Gran Nayar, comenzando por los "vecinos", los mestizos mexicanos con quienes interactúan cotidianamente. Ahora bien, con los procesos de globalización y el continuo acercamiento a los integrantes de otros pueblos originarios más distantes culturalmente hablando, queda la duda de quiénes de ellos se considerarían teiwari actualmente.

21- Antonio Resa de la Rosa, entrevista realizada el 05 e mayo de 2019 en El Colorín, mpio. de Del Nayar. 
base de la alimentación y el elemento-propósito principal de las fiestas, pero pasó a un segundo plano como actividad productiva. La caza, la pesca y la recolección, siguieron siendo actividades complementarias para su alimentación y el desarrollo del ritual.

\subsection{El arte huichol como palanca de empoderamiento para la mujer}

Doña Emilia asegura que eran "muy matadas” para el trabajo y que agradece que su papá y su mamá le hayan enseñado a trabajar. Doña Mariana orgullosa dice:

Yo sé de todo, menos de gurupera ${ }^{22}$ porque no soy burro, pero de todo. Sé bordar, se tejer, sé hacer puntas, sé de todo, de limpiar, de sembrar, de cargar, de todo, de hacer leña. [...] Yo desde ese tiempo que empecé a trabajar, nunca me he muerto de hambre (Mariana Ríos, 2019).

Ese tiempo al que se refiere, es el tiempo en que comenzó a hacer trajes y accesorios huicholes como morrales. En ese tiempo doña Mariana vivía sola, sus hijos e hijas son testigos de lo duro que trabajó para sacarlos adelante y no les faltara comida. Experiencia distinta a la que vivió uno de sus yernos, lo que cuenta:

Dice mi hija la más grande que está casada con un yerno que vive en Tepic. Que él le dice, [...] cuando nosotros estábamos con él [su papá] cómo pasábamos hambre. Y que le dice [mi hija]: fíjate lo que estás hablando, yo mi mama fue soltera y nunca nos murimos de hambre, yo la vi mi mama tejiendo, haciendo trajes, haciendo bolsas; iba a Tepic nos traiba un cargamento de mandado y dinero y ropa y guaraches nos traiba y otra vez se ponía a trabajar y a trabajar, iba a vender, nunca pasamos hambre, 'ora tu papa que era hombre... Te estabas muriendo tú de hambre, no mi mama, olvídate de mí mama como trabaja ella, dice. Y yo desde ese tiempo empecé a manejar yo sola mi dinero, yo si me casaba yo no era de que darle dinero a mi marido, porque, porque él no trabajaba, yo lo que vendía era mío y tampoco ellos no me preguntaban qué cuanto vendía que, que, tenía, porque él sabía que yo sola trabajaba. [...] cuando yo tenía dinero, mandaba tumbar mi cuamil. Pos que cincuenta pesos, dizque por cuatro tareas, yo creo sabe a como las pagaban. [...] Ya cuando venía [alguien a buscar trabajo en el jornal] ¿no cupas tareas en tu cuamil? Si le dije, ¿cuánto? Pos yo quiero pa cuatro, le pagaba. No hasta eso si cuamiliaba la gente. No, pues ya les ayudaban a mis hijos, tumbaban una dos, tres mediditas de cuamil, hay que irlo a quemar, hay que sembrar, hay que rociar, con todos mis chapulincitos por delante (Mariana, 2019).

La capacidad de doña Mariana de ser autosuficiente para cubrir sus necesidades y las de los suyos, puede estar relacionada con la independencia de propiedad que han practicado los wixaritari por muchos años y hasta la fecha. Doña Mariana como mujer sola en distintas etapas de su vida, encontró en la

22- Gurupera: "ataharre [...] cincha por bajo de la cola de caballo" (Código de las siete partidas, 1848:493). 
elaboración de artículos huicholes la posibilidad de mantener a sus hijos, además de poder trabajar sus tierras y financiar algunas de las actividades más demandantes físicamente como es coamilear. El maíz siguió siendo esencial para su alimentación y para la reciprocidad con los dioses, materializada en el cumplimiento de el costumbre.

\subsection{El arte chamánico}

En 1971 llegó a la región de El Colorín otro extranjero, Prem Das. Al parecer, desde el primer momento se sintió atraído por la espiritualidad de don José:

me impresionó profundamente a primera vista. Era la imagen exacta del don Juan de Carlos Castaneda: ochenta y seis años de edad, extremadamente en forma, irradiando exuberancia y vitalidad. [...] que él sea un pequeño hombre de cinco pies y cinco pulgadas de ninguna forma le resta su nobleza (Das, 1978: 129).

A partir de entonces, Prem Das junto con Eligio Carrillo, se convirtió en discípulo de don José (Matsiwa). Pronto llevó a su maestro a tierras estadounidenses donde don José realizaba ceremonias. Al igual que las piezas de arte huichol años atrás, los cantos que narran las historias sagradas, trascendieron el llamado territorio tradicional. Si bien la voz e instrumentos wixaritari de Ramón Medina parecen haber sido los primeros en escucharse en vivo en Estados Unidos de América, cuando se hace referencia a las ceremonias fuera del territorio tradicional, el pionero es don José Ríos (Matsiwa).

La eficacia de don José pronto lo hizo un famoso chamán entre amigos y seguidores de Das:

La ceremonia más extraordinaria con Don José tuvo lugar en Esalen a finales de los años setenta, durante una catastrófica sequía que duró varios años en California. Durante todo ese período la falta de agua fue dramática. La agricultura californiana estaba seriamente amenazada e incluso en las casas de lujo no se podía tirar de la cadena del cuarto de baño. Cuando la ceremonia estaba a punto de empezar, uno de los participantes propuso en broma: "Don José, hay una terrible sequía, tal vez podrías hacer la ceremonia de la lluvia”. Todo el mundo tomó la cosa a broma excepto Don José que, tras una breve pausa, aceptó.

Al no entender su canto en el idioma de los huicholes, la ceremonia nos pareció similar a otras que había realizado en el pasado [...] Al amanecer, Don José cogió de su bolsa de remedios una gruesa concha "oreja de mar" y una cola de conejo y nos invitó a ir con él al océano para recibir la limpieza, o purificación, y hacer ofrendas de agradecimiento al océano por la ceremonia.

Fuimos hacia las rocas cubiertas de cipreses de la estupenda costa de Big Sur, todavía bajo el "resplandor" de la ceremonia [...] Mientras el grupo al completo permanecía inmóvil observando el magnífico panorama, alguien advirtió que había empezado a lloviznar. "Increíble... imposible... fantástico..." fueron los comentarios sobre lo que, 
en medio de una terrible sequía, parecía un milagro. Pero Don José permaneció tranquilo. "Es kipuri, la bendición de los dioses", dijo. "Ocurre siempre, significa que hemos hecho una buena ceremonia".

Mientras bajábamos por los escalones de piedra hasta el océano, la llovizna se transformó en chaparrón. Don José llegó a la orilla, se paró sobre una roca plana, cuatro metros sobre el nivel del mar, depositó la ofrenda y empezó a cantar. Ese día el océano estaba en calma, pero, tras algunos minutos de oración, bajo nuestra mirada incrédula, se formó en la superficie una ola gigantesca que se dirigía rápidamente hacia la roca de Don José. La masa de agua alcanzó la roca con una fuerza tremenda, pero en su extremidad formó una cresta en forma de espiral que se llevó delicadamente las ofrendas, sin ni siquiera rociar los pies de Don José. En la mente de todos nosotros no hubo ninguna duda de que el extraordinario marảakame se había dirigido al océano como a un ser viviente y que éste le había respondido recibiendo sus ofrendas (Grof, 2008: 81-83).

Prem Das compraba y vendía arte huichol producido por la familia Ríos y otras de la región. Entre sus amigos se encontraba Brand Secunda, anteriormente llamado Paul Adams, pero conocido en la región de Aguamilpa como "Ricardo", el cual cerca de 1973 se convirtió en discípulo de don José. A principios de la década de 1980, Prem Das se retiró de la familia Ríos Medrano; a partir de los pleitos entre artesanos de Salvador Allende y La Mesita, pues según el relato de Epifanio (2018), ${ }^{23}$ los primeros le exigían les comprara solo a ellos. Ante la solicitud, Das decidió dejar de comprar, pero seguiría asistiendo a las fiestas con su familia política en Salvador Allende y de igual manera siguió llevando a don José a realizar ceremonias todavía varios años más.

Fue hasta 1990 cuando Prem Das ya no pudo viajar a tierras huicholas porque la policía mexicana le encontró varios kilos de peyote en el aeropuerto de Tepic (Fikes y Weigand, 2004). Ricardo tomaría el lugar de este, llevando a don José a realizar ceremonias en ciudades de Estados Unidos y Europa, además de la compra y venta de arte huichol. Durante dieciocho años Ricardo fue discípulo de don José, quien, a su muerte le dejo en su lugar y le encargo la protección de su familia.

\subsection{Transformaciones en los modos de vida}

Como ya se mencionó, la elaboración de arte huichol desplazó otras actividades productivas como la siembra del maíz, también impulsó otras. Fue el caso de la música: los Ríos de La Mesita aprendieron a puro oído a tocar guitarra y violines, instrumentos que compraron a partir de la venta de arte huichol, en pocos años todos los hombres hijos de don José, algunos de sus yernos y nietos aprenderían también. En grupos de cuatro o cinco recorrerían comunidades tanto de la costa como de la sierra tocando y cantando música regional.

Para esa época, las casas ya las hacían de materiales más duraderos porque tenían los recursos económicos y humanos para hacerlas. Aun así, seguían en constante movimiento: de La Mesita se fueron a

23- Epifanio Ríos Medrano, entrevista relizada en Tepic, Nayarit, el 27 de junio de 2018.

Eduardo Mejía Rodríguez / Jorge Luis Marín García / Efraín Rangel Guzmán 
Salvador Allende y de ahí a Las Blancas; no se puede dejar de lado las migraciones a la costa por periodos de dos a tres meses que continuaban. De igual forma las idas a tocar a la sierra también duraban días. En las comunidades las tareas correspondientes a cada género se mantenían, en muchos casos las hermanas mayores se encargaban de sus hermanos cuando sus padres iban a la costa, allá, las mujeres primero echaban lonche y después ayudaban en las tareas o faenas. Las idas más dentro en la sierra solo las realizaban los hombres, quienes durante el tiempo que permanecían fuera pagaban por la comida.

Se puede decir que la música es resultado del tiempo libre, dedicaban muchas horas por las tardes a aprender canciones y a enseñar a los otros, aunque luego era una combinación de tiempo de ocio y actividad productiva. Otra actividad del tiempo libre fue el voleibol, el cual jugaban donde estuvieran, en ocasiones por dinero. Algunos cuentan que la elaboración del arte huichol, era trabajo fácil y lo llegaban a hacer en su tiempo libre y recibían buen pago por él.

Las redes de relaciones políticas y económicas construidas por parte de don José y familia con funcionarios de gobierno, además de la capacidad económica adquirida a partir de la elaboración y venta del arte huichol, permitió culminar el proceso de aproximadamente catorce años que llevaron los trámites y solicitudes para que finalmente en 1986 les reconocieran como ejido El Colorín, recibiendo así, los títulos de propiedad.

Con la propiedad llegarían también problemas. La figura de don José ya no tenía el peso para mediar entre ellos, todos eran adultos y desde la trinchera personal defendían el derecho a la propiedad de las tierras, incluso quienes ya no habitaban en ellas, por ejemplo los hijos de don José que le siguieron cuando se mudó en primera instancia a Salvador Allende y después a Las Blancas.

\section{El legado de don José Ríos (Matsiwa)}

Don José, el campesino huichol nacido a finales del siglo XIX, convertido en mara'akate seis décadas después, y llevado a Estados Unidos de América y Europa a principios de la década de los setenta para realizar ceremonias de sanación multitudinarias, organizadas por Prem Das y Secunda, en poco tiempo adquirió, según Epifanio (2018), más de cien reses y una cuenta en el banco con una cantidad importante de dinero. Cifra desconocida en su monto real.

A finales de los ochenta, por invitación de sus sobrinos, se traslada a Salvador Allende con la mayoría de sus hijos, hijas y el ganado, con la intención de estar un poco más cerca de Tepic, para facilitar sus constantes viajes al extranjero. La falta de tierras para pastar su ganado le acarrea problemas, sus vacas dañan dos cuamiles, por los cuales paga mucho dinero y eso le obliga a moverse al poblado Las Blancas, en la misma región. En 1990 fallece don José (Matsiwa), y su esposa se traslada a El Ciruelar, para estar al pendiente de unas pocas vacas que le quedaron.

Don José dejó una familia numerosa, un legado cultural importante y redes de relaciones que se construyeron a lo largo de la historia. Seguir los pasos de los antepasados, o realizar el costumbre, son elementos que están cargados de simbolismos que permiten comprender el mundo desde sus lógicas, mitos, relatos y narrativas. Estos elementos le permiten al individuo interpretar al otro, interpretar al mundo y en consecuencia actuar (Lindón, 2000: 10). Por ello, la cotidianeidad es el reflejo de lo social en su historicidad, estructuras y socialización. Así, lo que hoy se ve como cotidiano, tiene una carga histórica importante. Como señala Uribe (2014: 102) "la trama de un día contiene fragmentos de la historia 
del mundo desde las realidades locales, regionales y nacionales, lo cual, representa una forma clara de abordar la relación de los aspectos micro y macro para el análisis de los procesos sociales". En sentido de lo anterior, en El Colorín, florecieron diversos oficios con la acumulación de historias y tramas: violeros, artistas, parteras, curanderas y pescadores, sólo por mencionar algunos.

Mientras vivió don José, fueron muchos los teiwarixi que llegaron a El Colorín, varios de ellos siguieron yendo tras su muerte. Por ejemplo, Fikes (2009: 97) relata que Marie-Aretí Hers, entrevistada en 1990 por Celia García-Wiegand, señalaba en relación a un viaje que realizó a El Colorín en 1971 junto a Marina Anguiano y su esposo: "estaba asombrada por el hecho de que todos los huicholes jóvenes de El Colorín fueran tan comunicativos. Hablaban español y anticipaban las preguntas que sus visitantes podían formular acerca del significado ritual. Al parecer estaban acostumbrados a tratar con antropólogos". De hecho, para Fikes lo narrado muestra que lo que ahí se mira no es lo tradicional, como si lo tradicional pudiera ser dictado por reglas eternas.

Lo que nos permite reflexionar lo narrado por Fikes acerca de Hers, es que los habitantes de El Colorín crean lo que Berger y Luckman (1986) llaman "esquemas tipificadores", esquemas creados culturalmente a partir de los cuales se entiende el mundo, y nos relacionamos con los demás seres humanos. En lo aquí descrito estos son usados para tratar al otro en situaciones "cara a cara" como la anteriormente descrita, donde se aprecian jóvenes acostumbrados a tratar con antropólogos, ávidos de informar y que dominan el español. Su actuar es el resultado de un aprendizaje continuo que se había empezado a construir antes de 1966, pero que se refuerza luego de la llegada de Furst y demás teiwarixi, integrando a su vida cotidiana esquemas para tratar a los antropólogos y con ello a otros teiwarixi, como las autoridades de la Comisión Federal de Electricidad (CFE) encargadas de construir y poner en marcha la Presa de Aguamilpa en la década de 1990. En un momento de este entramado de historias, la mayoría de los integrantes de la familia Ríos, dejan de celebrar al menos una de las Fiestas relacionadas con el ciclo agrícola, la Fiesta de la Limpia.

\section{Conclusión}

A grandes rasgos, las actividades que construyen la realidad social de los habitantes de El Colorín, están cargadas de esquemas de significados que permiten interpretar la realidad ahí construida, gracias a eventos y lugares pasados y presentes que dan como resultado modos de vida que construyen la realidad en el poblado. De esa manera, en una rápida revisión de la forma en que se estructuraba la vida cotidiana de Jose Ríos y los Ríos Medrano agricultores, en comparación con los Ríos Medrano artesanos y los Ríos Medrano y sus descendientes pescadores, podemos comprender las transformaciones y reacomodos que sucedieron para llegar a lo que ahora acontece en El Colorín. Los ritmos socioculturales, y los ritmos siderales se articulan en forma distinta a lo largo del tiempo: un ritmo determinado por la aparición del sol y la luna o por las estaciones va dejando más espacio a un ritmo determinado por el calendario, el reloj, y la demanda por artesanía. Pero no es un giro absoluto, el tiempo sideral sigue normando parte de la vida cotidiana en la religión y "el tiempo de oquis", de la mano del tiempo que en algún momento fue el tiempo teiwari, pero que ahora puede ser un tiempo sociocultural teiwari y wixarika.

Los espacios en que se crean y se recrean los aspectos culturales de los habitantes de El Colorín, son aquellos donde interactúan lo teiwari y lo wixarika, en procesos acelerados de intercambio cultural, económicos, 
políticos, etc. La llegada de antropólogos a partir de 1965, provocó transformaciones a partir de que se da una apreciación por los productos elaborados por los artistas huicholes, además de los accesorios, vestimenta, cultura y los rituales. Ello propició nuevos esquemas de interacción entre wixaritari, y teiwarixi nacionales y extranjeros interesados en conocer su cultura, motivando una dinámica de conservación y pérdidas en diferentes elementos de la misma.

A partir de los cambios en las actividades productivas, no desaparece la cultura wixarika, pero sí hay una disminución en varias prácticas: no se están preparando mara'akate en la comunidad; algunos señalan que existe falta de compromiso o desconocimiento por parte de los más jóvenes en la realización de las fiestas; varios no realizan el ayuno y la abstinencia como se indica para la realización de diversas actividades; se están perdiendo saberes tradicionales en relación a la salud, la educación, la lengua, el trabajo y la costumbre en general. Ahora bien, desde fuera se señala la venta de la cultura huichola en un mundo capitalista como algo negativo; sin embargo, muchos de los locales, desde su narrativa, recuerdan con alegría el inicio de la venta de la artesanía, se dicen orgullosos por ser reconocidos y apoyados para mantener sus prácticas culturales; no sólo hablan de dinero, pero si aspiran a tenerlo.

Las diferencias culturales entre los wixaritari de Nayarit y los de Jalisco son realmente significativas y de igual manera hay todavía un nucleo importante de tradición que comparten; empero, es difícil establecer hsta donde existen tales diferencias y tradición compartidas porque la investigación enfocada realmente en los wixaritari del estado de Nayarit todavía es poca. Falta mucho por conocer, desde un enfoque constructivista, en cuanto a estructura socioreligiosa en las distintas localidades, sobre sistemas de cargos, transformaciones económicas, productivas y socioculturales, cuestiones históricas de los asentamientos, vida cotidiana en contextos mayoritariamente teiwari, historia del arte huichol, entre muchos otros temas.

\section{Referencias}

Berger, Peter y Thomas Luckman. 1986. La construcción social de la realidad. Buenos Aires: AmorrortuMurguía.

Código de las siete partidas. 1848. Madrid: , Publicidad.

Das, Prem. 1978. Initiation by a Huichol shaman. En Art of the Huichol Indians, editado por Kathleen Berrin. New York: Fine Arts Museum of San Francisco, Harry N. Abrams, 129-141.

Fikes, Jay. 2009. Carlos Castaneda, oportunismo académico y los psiquedélicos años sesenta. USA: Xlibris Corporation.

y Phil Wiegand. 2004. Sensacionalismo y etnografía: el caso de los huicholes de Jalisco. Relaciones. Estudios de historia y sociedad, 25 (98): 49-68.

Godoy, Luis. 2004. Modos de hablar en Jalisco. México: Secretaría de Cultura. Gobierno del Estado de Jalisco.

Grof, Stanislav. 2008. Cuando Ocurre lo Imposible. Aventuras en realidades no ordinarias. Barcelona: La liebre de marzo.

Jaúregui, Jesús. 2003. Cómo los huicholes se hicieron mariacheros: el mito y la historia. En Flechadores de estrellas. Nuevas aportaciones a la etnología de coras y huicholes, coordinado por Jesús Jaúregui y Johannes Neurath. México: INAH/ U. de G., 341-385. 
D’Epinay, Christian. 2008. La vida cotidiana: construcción de un concepto sociológico y antropológico. Sociedad Hoy, (14): 9-31.

Lefebvre, Henri. 1981. Critique de la vie quotidienne. Vol. III: De la modernité au modernisme (Pour une métaphilosophie du quotidien). París: L’Arche Editeur.

Liffman, Paul. 2005. Fuegos guías y raíces. Relaciones, XXVI (101): 51-79.

Lindón, Alicia. 1997. El trabajo y la vida cotidiana. Un enfoque desde los espacios de vida. Economía Sociedad y Territorio, 1 (1): 177-197.

(Coord.). 2000. La vida cotidiana y su espacio-temporalidad. México: UNAM., Anthropos

Editorial.

2011. Cotidianidades territorializadas entre la proxemia y la diastemia: Ritmos espaciotemporales en un contexto de aceleración. Educación Física y Ciencia, 13: 15-34.

Marín, Jorge. 2011. Rituales y arte huicholes: espacios de frontera entre la sierra y el pavimento. Tesis de doctorado en ciencias humanas con especialidad en estudios de las tradiciones. Zamora: El Colegio de Michoacán A.C.

Meyer, Jean. 1997. Breve historia de Nayarit. México: El Colegio de México, Fideicomiso Historia de las Américas.

Rocha, Martha. 2015. Visión panorámica de las mujeres durante la Revolución Mexicana. En Historia de las mujeres en México. México: Instituto Nacional de Estudios Históricos de las Revoluciones de México, 201-224.

Santos, Saúl. 2017. Hacia un modelo comunitario revitalización del huichol: caso El Colorín. En Lenguas minorizadas: ¿Qué hacer para registrar y preservar una lengua?

Aproximaciones a la documentación lingüística, editado por Cynthia Montaño, Inocencia Arellano y Luis Sánchez. Querétaro: Universidad Autónoma de Querétaro, 199-215.

Tellez, Víctor. 2005. Territorio, gobierno local y ritual en Xatsitsarie : Guadalupe Ocotán Nayarit. Tesis de doctorado en antropología. Zamora: El Colegio de Michoacán A.C.

y Le Mûr, Rozenn. 2017. De la sierra a la ciudad. Identidad y participación económica de los huicholes de Guadalupe Ocotán en la ciudad de Tepic. En Explorando nuevas miradas en los estudios del agua y en las transformaciones socioterritoriales en el occidente de México, editado por Octavio González y Alicia Torres. Zamora: El Colegio de Michoacán A.C., 183-211.

Uribe, Mary. 2014. La Vida Cotidiana como espacio de construcción social. Procesos Históricos, (25): 100-113. 